\title{
RADIOIMMUNOASSAY MEASUREMENT OF LUTEINIZING HORMONE EXCRETION RATES FOLLOWING BILATERAL OOPHORECTOMY
}

\author{
A. HILARY ORR, AUDREY P. WARD AND K. D. BAGSHAWE \\ Edgar Laboratory, Fulham Hospital, St. Dunstan's Road, London, W.6, and \\ Department of Obstetrics and Gynaecology, St. Mary's Hospital Medical School, \\ London, $W .2$
}

(Received 27th November 1968)

\begin{abstract}
Summary. The excretion of LH in a group of women subjected to bilateral oophorectomy is studied, using a radioimmunoassay method. The results are compared with those obtained by other methods and their usefulness as a basis for clinical interpretation of LH estimations by this method is discussed.
\end{abstract}

\section{INTRODUCTION}

Gonadotrophic activity was first identified in the urine of post-menopausal women by Zondek (1929) and in the blood of oophorectomized women by Fluhmann (1929). Radioimmunoassay techniques permit luteinizing hormone $(\mathbf{L H})$ to be estimated in unextracted urine or plasma (Bagshawe, Wilde \& Orr, 1966), whereas bioassay estimates have usually been performed on urine extracts (Albert, 1956; Johnsen, 1959; Brown, 1963; Loraine \& SchmidtElmendorff, 1963). The speed and simplicity of the radioimmunoassay techniques allow large numbers of assays to be carried out in a short time and thus make detailed studies of gonadotrophin excretion practicable. Excretion rates in various groups of subjects of known endocrine status need to be established by radioimmunoassay in order to provide a basis for the clinical interpretation of results. In this paper, excretion rates determined by this method in women immediately following oophorectomy are presented and compared with those reported by bioassay and other immunoassay methods.

\section{MATERIALS AND METHODS}

Luteinizing hormone activity in urine was measured by radioimmunoassay (Wilde, Orr \& Bagshawe, 1967). Estimates were made against the 2nd International Reference Preparation of human menopausal gonadotrophin (2nd IRP HMG) or against a laboratory sub-standard of human chorionic gonadotrophin (HCG), which gave a parallel response to HMG in this assay. The results are expressed in terms of International Units (Immunoassay) of LH (2nd IRP HMG). 
Specificity of the assay method

The specificity, sensitivity and reproducibility of the method have been presented elsewhere (Bagshawe et al., 1966; Wilde et al., 1967). Odell, Wilber \& Paul (1965) have suggested that LH may share antigenic groups with FSH and TSH. Antisera appear to vary in the amount of cross-reaction which they show. In the present assay system, assay of the most highly purified preparations available of LH, FSH and TSH suggests that if FSH and TSH do contribute to the measured response, their contribution is small compared with that of $\mathrm{LH}$.

\section{Samples}

All estimates were made on 24-hr collections of urine preserved with thiomersal. As the assay was sensitive to 0.01 i.u. $\mathrm{LH} / \mathrm{ml}$, no extraction or concentration of the urine was required. The subjects in Group A made one preoperative urine collection and daily collections after that as long as they were in hospital. After discharge, they made collections once weekly for 8 weeks. These collections were made under normal ambulant conditions, as were the collections of the Groups B and C. Groups B and C made similar 24-hr collections at various intervals.

\section{Subjects}

Group $A$ (women undergoing oophorectomy) consisted of seven females, aged 33 to 62 years, who underwent bilateral oophorectomy and hysterectomy for irregular bleeding or fibroids. All, except one patient, were aged 45 or more. Some of these subjects were given oestrogens post-operatively. One (J.A.) received an oestrogen implant at the time of oophorectomy (oestradiol, 50 $\mathrm{mg}$ ) and another (S.S.) took an oral oestrogen-progestagen compound (Enavid E; norethynodrel $2.5 \mathrm{mg}$, mestranol $0.1 \mathrm{mg}$; G. D. Searle) throughout the period of observations. A third subject (M.M.) received stilboestrol $(0.5$ $\mathrm{mg} /$ day) for 1 month following oophorectomy and a fourth (F.F.) received stilboestrol $(0.5 \mathrm{mg} /$ day $)$ from the 7 th week after oophorectomy.

Group $B$ (oophorectomized controls) consisted of eight females aged 20 to 52 years who made $24-\mathrm{hr}$ urine collections at intervals. One subject, aged 20 , had previously undergone bilateral oophorectomy for lutein cysts. The other seven subjects had previously undergone bilateral oophorectomy at surgery for malignant disease. One of these patients, aged 32 years, had had a tumour of the uterus. The other six had been treated for choriocarcinoma and had no evidence of residual disease during a follow-up of at least 2 years. Since relapses have not occurred in any of a large series of patients with choriocarcinoma who have been in remission for more than 6 months, these cases are considered to be normal, oophorectomized subjects.

Group $C$ (non-oophorectomized controls) consisted of eight pre-menopausal subjects, aged 23 to 30 years, who made daily urine collections for several weeks. Five had previously had trophoblastic tumours which regressed completely, either spontaneously or during chemotherapy. All were menstruating normally and urine collections were made at regular intervals as part of the follow-up procedure for this disease. All these subjects have remained in normal health. 


\section{RESULTS}

The results are presented in Text-figs. 1 and 2.

Three subjects in Group A, who were aged 48 to 62 years, had high LH excretion rates in the samples obtained immediately before oophorectomy, but the others were in the normal pre-menopausal range. Following oophorectomy, high excretion rates were observed within a few days in the three subjects who did not receive oestrogens. In four subjects, $\mathbf{L H}$ excretion rates frequently exceeded 300 i.u. LH/day and in three of these, values in excess of $600 \mathrm{i} . \mathrm{u}$. LH/day were found. In the subjects who received oestrogens after oophorectomy, LH values remained in, or close to, the pre-menopausal range.
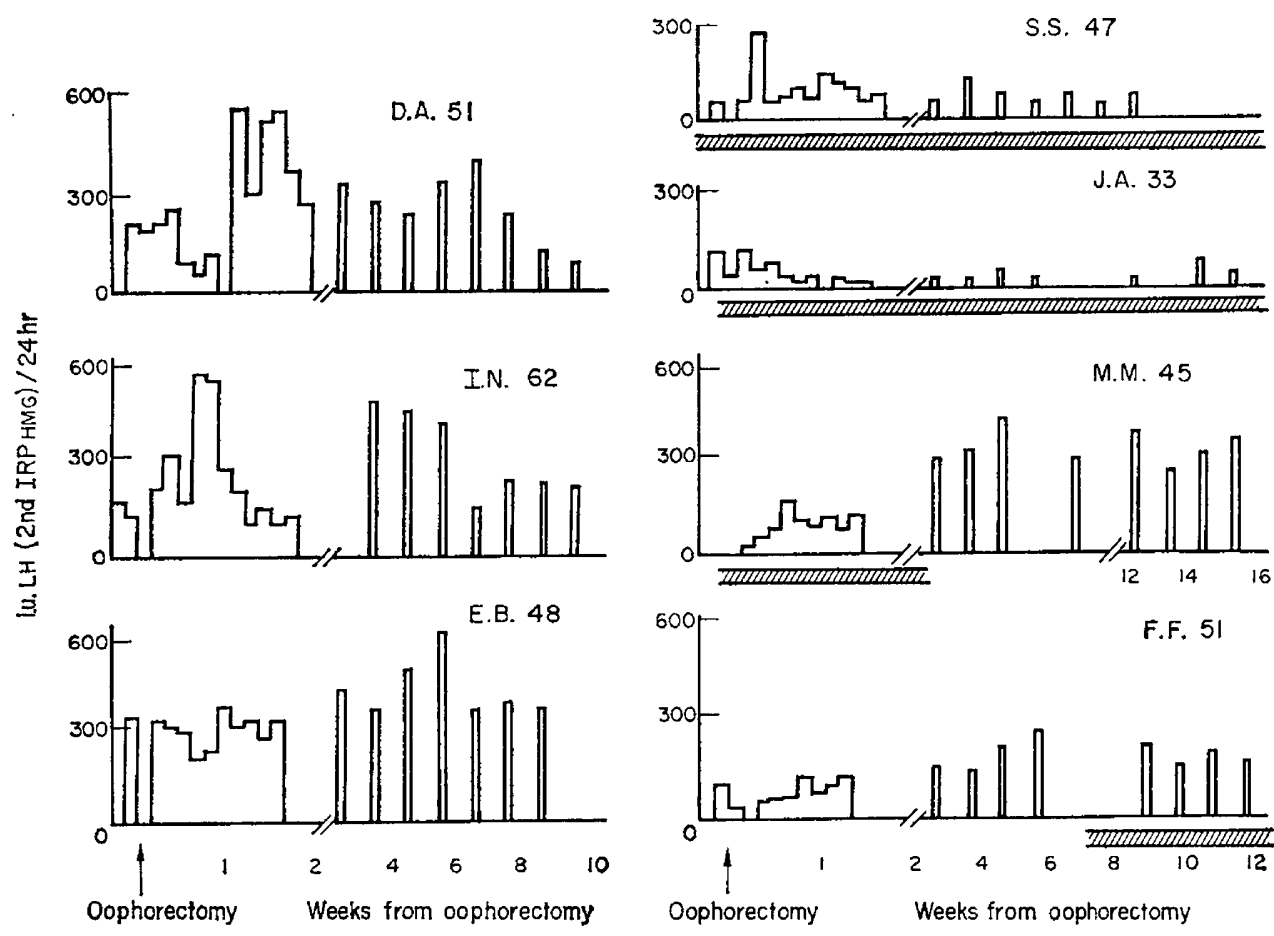

TEXT-FIG. 1. Serial 24-hr excretion values of luteinizing hormone for seven patients before and after oophorectomy. Plain bars indicate 24-hr urinary excretion values for LH. Hatched areas indicate duration of oestrogen treatment.

The post-menopausal subjects in the control Group B had excretion rates in the range 35 to 810 i.u./day. Substantial variations in output were noted in some subjects studied on different days, whereas other subjects had relatively constant excretion rates. The mean value of the eighty estimations for this group was 252 i.u. LH/day (S.E. \pm 19 i.u.).

The pre-menopausal subjects in the control Group $\mathrm{C}$ had excretion rates ranging from 15 to $350 \mathrm{i}$.u. $\mathrm{LH} /$ day with a mean value for the eighty estimations of 58 i.u./day (S.E. \pm 6 i.u.). The higher values in this group occurred at midcycle. 


\section{DISGUSSION}

There have been few studies of gonadotrophin excretion immediately following castration and it is notable that in the present study, peak values of excretion were reached only 4 days post-oophorectomy and in other instances within 10 days of operation. Values in the upper half of the post-menopausal range were maintained over the next few weeks, in the absence of administered oestrogens. Oestrogens were administered post-operatively to several of the subjects (Text-fig. 1). The resultant gonadotrophin excretion rates contrast sharply with those of the untreated group and are suppressed to the normal or near normal pre-menopausal range.

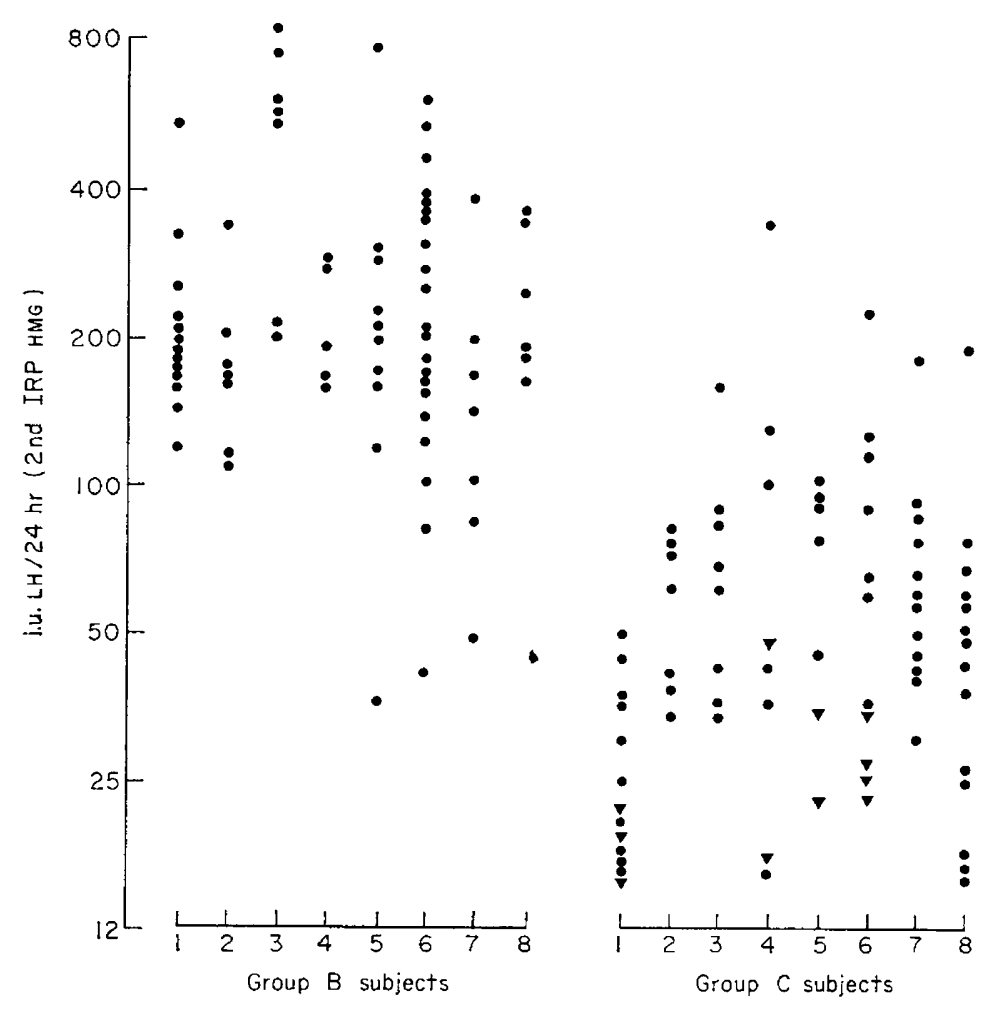

TEXT-FIG. 2. 24-hr LH excretion values of oophorectomized (Group B) and pre-menopausal (Group C) subjects. $\bullet, 24-\mathrm{hr}$ urinary excretion values for $\mathrm{LH} ; \nabla, 24-\mathrm{hr}$ urinary excretion of LH less than value indicated - LH concentration below limit of sensitivity of assay used.

Previous estimates of gonadotrophin excretion in post-menopausal women have been made mainly by bioassay on urine extracts. Direct comparison of excretion rates is difficult because of the variety of reference standards employed and the influence of the source of reference preparations on bioassay estimates (Rosemberg, Solod \& Albert, 1964). Some of the bioassay methods are relatively specific for LH whereas others, such as the mouse uterine weight method, respond to the synergistic action of LH and FSH and are therefore non-quantitative procedures. A limited basis for comparison of results of different assay methods is provided by the ratio of post-menopausal to normal male values (Table 1). 


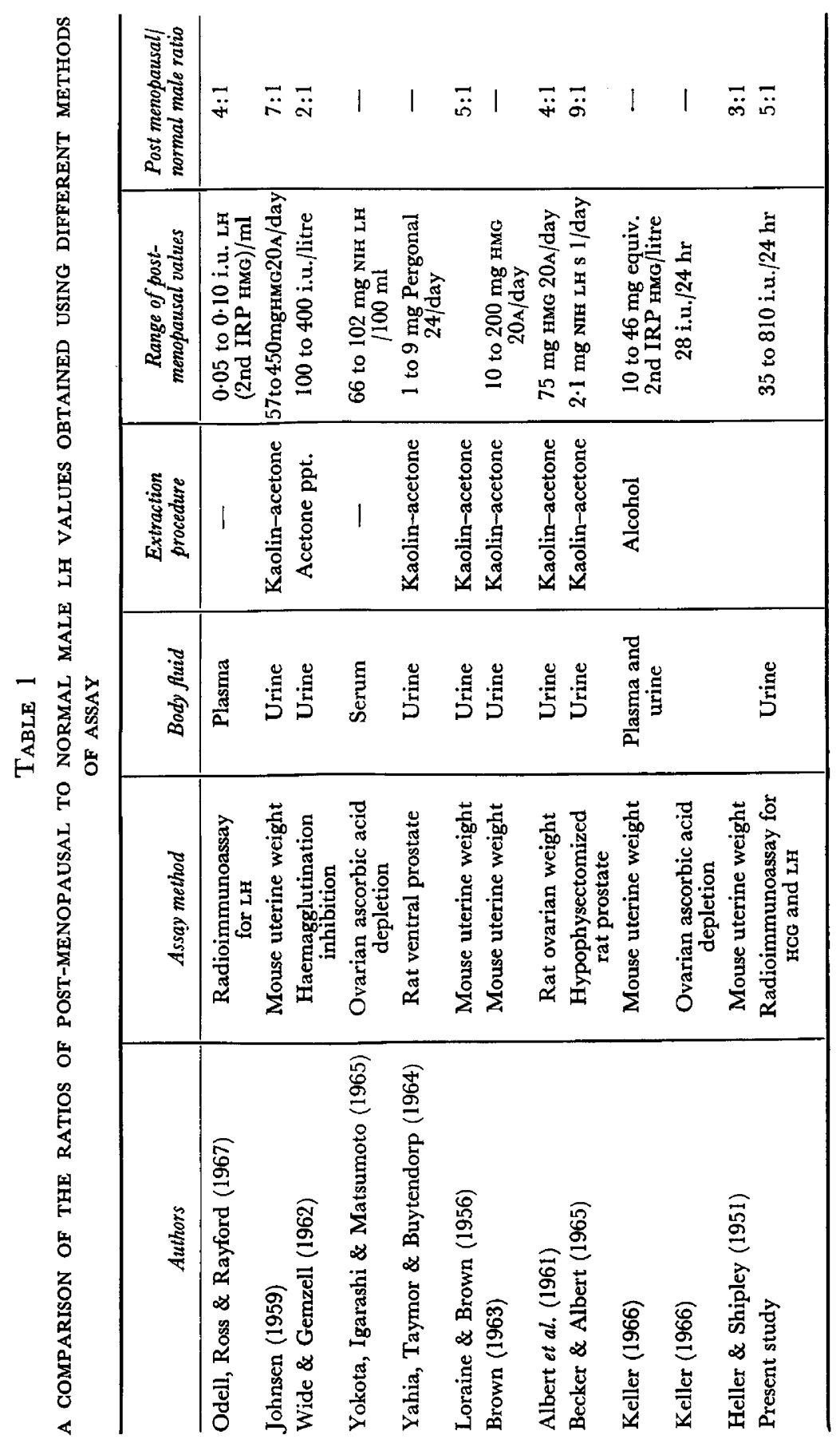


These ratios have ranged from $3: 1$ to $9: 1$ by bioassay, and from $2: 1$ to $5: 1$ by immunoassay. The assay described here gives a ratio of $5: 1$, (mean value of fifteen estimations on normal male subjects was 49 i.u. LH/day S.E. \pm 7 i.u.) which is close to the estimate of 4:1 of Odell, Ross \& Rayford (1967) who reported radioimmunoassay of $\mathrm{LH}$ activity in serum.

Johnsen (1959) reported that the day-to-day variation in gonadotrophin excretion by post-menopausal females in a mouse uterine weight assay was only slightly greater than the variation attributable to the assay itself. Albert \& Mendoza (1966), using the rat ovarian weight method found a two-fold fluctuation in day-to-day gonadotrophin excretion rate, and Yahia, Taymor \& Buytendorp (1964) made a similar observation using the rat. The present results support the observations that day-to-day variations can be substantial, even in women several months after oophorectomy.

Such variations emphasize that estimates of pituitary and gonadal function, based on a single urine collection, may be misleading and that a series of samples is likely to be required for many clinical purposes. The present evidence indicates the need for assay methods which can be performed on a scale appropriate to clinical requirements and the potential value of radioimmunoassay measurements of $\mathbf{L H}$ in the clinical assessment of pituitary and gonadal function.

\section{REFERENCES}

Alsert, A. (1956) Human urinary gonadotropin. Recent Prog. Horm. Res. 12, 227.

Albert, A., Derner, I., Leifermann, J., Stellmacher, V. \& Barnum, J. (1961) Studies on biologic characterization of human gonadotropins. VII. Urinary gonadotropins of men, post-menopausal women and eunuchs. 7. clin. Endocr. Metab. 21, 839.

Albert, A. \& Mendoza, D. (1966) Daily fluctuation in excretion of follicle-stimulating and luteinizing hormones by a post-menopausal woman. . clin. Endocr. Metab. 26, 371.

Bagshawe, K. D., WiIDE, C. E. \& ORR, A. H. (1966) Radioimmunoassay for human chorionic gonadotrophin and luteinizing hormone. Lancet, i, 1116.

BzGKer, K. L. \& Albert, A. (1965) Urinary excretion of follicle-stimulating and luteinizing hormones. 7. clin. Endocr. Metab. 25, 962.

Brown, P. S. (1963) Urinary gonadotrophins in post-menopausal women. F. Endocr. 25, 427.

Fluhman, C. F. (1929) Anterior pituitary hormone in blood of women with ovarian deficiency. 7. Am. med. Ass. 93, 672.

Heller, A. L. \& Shipley, R. A. (1951) Endocrine studies in aging. F. clin. Endocr. Metab. 11, 945.

JohNSEN, S. G. (1959) A clinical routine method for the quantitative determination of gonadotrophins in 24-hour samples. II. Normal values for men and women at all age groups from pre-puberty to senescence. Acta endocr., Copenh. 31, 209.

Keller, P. J. (1966) Studies on pituitary gonadotrophins in human plasma. I. Normal values in men and women of all ages. Acta endocr., Copenh. 52, 341.

LoRAINe, J. A. \& BROWN, J. B. (1956) Further observations on estimation of urinary gonadotropins in non-pregnant human subjects. F. clin. Endocr. Metab. 16, 1180.

Loraine, J. A. \& Schmidt-Elmendorff, H. W. (1963) Human gonadotrophins. In: Modern Trends in Human Reproductive Physiology, pp. 18-44. Ed. H. M. Carey. Butterworth, London.

Odell, W. D., Ross, G. T. \& RAyford, P. L. (1967) Radioimmunoassay for luteinizing hormone in human plasma or serum: physiological studies. F. clin. Invest. 46, 248.

Odeli, W. D., WiLber, J. F. \& PAUL, W. E. (1965) Radioimmunoassay of thyrotropin in human serum. 7. clin. Endocr. Metab. 25, 1179.

Rosemberg, E., Solod, E. A. \& AlBerr, A. (1964) Luteinizing hormone activity of human pituitary gonadotropin as determined by the ventral prostate weight and the ovarian ascorbic acid depletion methods of assay. Endocrinology, 24, 714.

WIDE, L. \& GeMzeLL, C. (1962) Immunological determination of pituitary luteinizing hormone in the urine of fertile and postmenopausal women and adult men. Acta endocr., Copenh. 39, 539.

Wilde, C. E., OrR, A. H. \& Bagshawe, K. D. (1967) A sensitive radioimmunoassay for human chorionic gonadotrophin and luteinizing hormone. F. Endocr. 37, 23. 
YAHIA, C., TAYMoR, M. L. \& BuYtendoRP, A. (1964) Day to day variation in LH excretion in carcinoma of the endometrium and normal menopause. Am. F. Obstet. Gynec. 88, 730.

Yokota, N., Igarashi, M. \& Matsumoto, S. (1965) Human serum luteinizing hormone (Lh) levels during the normal menstrual cycle and after ovariectomy. Endocr. jap. 12, 92.

ZoNDEK, B. (1929) Weitere Untersuchungen zur Darstellung, Biologie und Klinik des Hypophysenvorlappenhormons (Prolan). Zentbl. Gynäk. 53, 834. 